\title{
PELATIHAN MEDIA PEMBELAJARAN BERBASIS ANDROID BAGI TUTOR PENDIDIKAN KESETARAAN PADA PKBM DI KECAMATAN SUKAMAKMUR KABUPATEN BOGOR JAWA BARAT
}

\author{
Anan Sutisna', Ahmad Tijari² dan Adi Irvansyah ${ }^{3}$

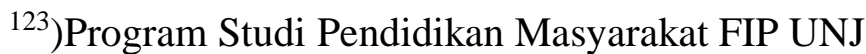 \\ $\left.{ }^{1}\right)$ asutisna@unj.ac.id ${ }^{2}$ )ahmadtijari-pls@unj.ac.id ${ }^{3}$ ) adiirvansyah-pls@unj.ac.id
}

\begin{abstract}
Based on the analysis of the situation and conditions of the community in Sukamakmur Sub-District, Bogor District of West Java, especially in the field of education, it is necessary to have an Android-based learning media development training activity to support the improvement of Tutor and Manager Competencies so that the learning process in Community Learning Center is of higher quality. The specific objectives of community service activities integrated with real work lectures are as follows: (1) Improving the ability of tutors and managers in planning learning using Android-based learning media, (2) Improving the ability of tutors and managers in using Android-based learning media and (3) Guide tutors and managers in implementing learning using Android-based learning media. This Community Service Integrated Community Service activity was carried out for four months from July to October 2019

The results show learning in Community Learning Center by using Andoid-based learning media as an effort to strengthen students' understanding of the material presented, and students can access it wherever they are to overcome the problems of students whose homes are far from Community Learning Center. Teaching using Android-based media is also able to emphasize the practice of digital literacy directly which still refers to the concept of learning media theory for equality education. Learning using Android-based media can be used wherever students are located, and therefore the independence of students will increase because without the presence of educators, students are able to operate it. The presentation provided is able to attract students 'interest, because it contains a material that is presented via video, so that students do not feel bored and fed up, because the media can stimulate students' ability to see and hear.
\end{abstract}

Keywords: Training, Learning media, Android, Equality Education

\begin{abstract}
Abstrak
Berdasarkan hasil analisis siatuasi dan kondisi masyarakat di Kecamatan Sukamakmur Kecamatan Kabupaten Bogor Jawa Barat khususnya dalam bidang pendidikan, maka diperlukan adanya kegiatan pelatihan pengembangan media pembelajaran berbasis Android untuk mendukung peningkatan Kompetensi Tutor dan Pengelola agar proses pembelajaran di PKBM lebih berkualitas. Adapun tujuan secara khusus kegiatan pengabdian kepada masyarakat yang terintegrasi kuliah kerja nyata adalah sebagai berikut: (1) Meningkatan kemampuan tutor dan pengelola dalam merencanakan pembelajaran dengan menggunakan media pembelajaran berbasis Android, (2) Meningkatkan kemampuan tutor dan pengelola dalam menggunakan media pembelajaran berbasis Android dan (3) Memandu tutor dan pengelola dalam melaksanakan pembelajaran menggunakan media pembelajaran berbasis Android. Kegiatan Pengabdian kepada masyarakat terintegrasi KKN ini dilakukan selama empat bulan mulai Juli sampai dengan Oktober 2019.

Hasil menunjukkan pembelajaran di PKBM dengan menggunakan media pembelajaran berbasis Andoid sebagai upaya menguatkan pemahaman peserta didik terhadap materi yang disajikan, dan peserta didikpun dapat mengaksesnya dimanapun ia berada untuk mengatasi persoalan peserta didik yang tempat tinggalnya jauh dari PKBM. Pengajaran menggunakan media berbasis android ini juga mampu menekankan pada praktik literasi digital secara langsung yang tetap mengacu pada konsep teori media pembelajaran untuk pendidikan kesetaraan. Pembelajaran menggunakan media berbasis Android mampu digunakan dimana saja peserta didik itu berada, maka dari itu kemandirian peserta didik akan meningkat karena tanpa kehadiran pendidikpun, peserta didik mampu mengoperasikannya. Penyajian yang disediakanpun mampu menarik minat peserta didik, karena berisi sebuah materi yang disajikan melalui
\end{abstract}


video, sehingga peserta didik tidak merasa bosan dan jenuh, karena media tersebut dapat merangsang kemampuan melihat dan mendengar peserta didik.

Kata Kunci: Pelatihan, Media pembelajaran, Android, Pendidikan Kesetaraan

\section{PENDAHULUAN}

\section{Analisis Situasi}

Mencerdaskan kehidupan bangsa merupakan amanah UUD 1945 dan sudah 71 tahun Indonesia merdeka, tidak semua masyarakat dapat memiliki kesempatan dan akses dalam mengenyam pendidikan formal. Kesempatan untuk meraih pendidikan melalui jalur pendidikan formal tidak selalu dimiliki oleh masyarakat, berdasarkan hal ini pendidikan non formal menjadi alternatif untuk mencerdaskan masyarakat terutama masyarakat yang kurang beruntung menempuh pendidikan formal karena berbagai sebab baik ekonomi, jarak yang ditempuh, persepsi masyarakat tentang

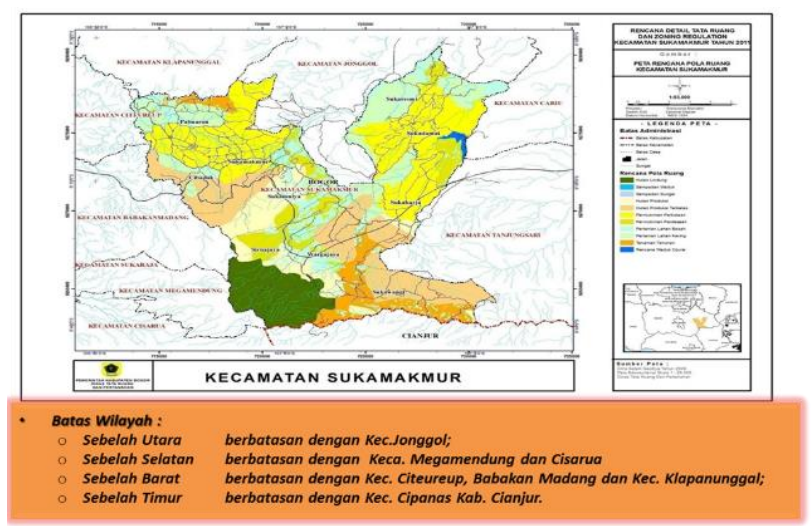

pendidikan serta berbagai kendala lainnya (Rifai : 2009). Mendapatkan kesempatan menempuh pendidikan diperoleh melalui Pusat Kegiatan Belajar Masyarakat (PKBM). Kehadiran PKBM sangat berguna bagi masyarakat untuk melanjutkan pendidikan ke jenjang yang lebih tinggi.

Kecamatan Sukamakmur adalah salah satu kecamatan yang ada di Kabupaten Bogor Provinsi Jawa Barat. Terdiri atas sepuluh desa yaitu: Desa Sukamakmur, Pabuaran, Cibadak, Sirnajaya, Sukadamai, Sukamulya, Wargajaya. Sukaresmi dan Desa Sukawangi. Adapun petanya pada gambar di bawah ini:

Gambar 1. Sebaran sekolah yang ada di Kecamatan Sukamakmur

Berdasarkan hasil wawancara dengan pihak kecamatan Sukamakmur, selain Pendidikan Formal, hadir juga Pusat Kegiatan Belajar Masyarakat (PKBM). PKBM di Kecamatan Sukamakmur tersebar di beberapa desa yaitu Pabuaran, Sukaharja dan

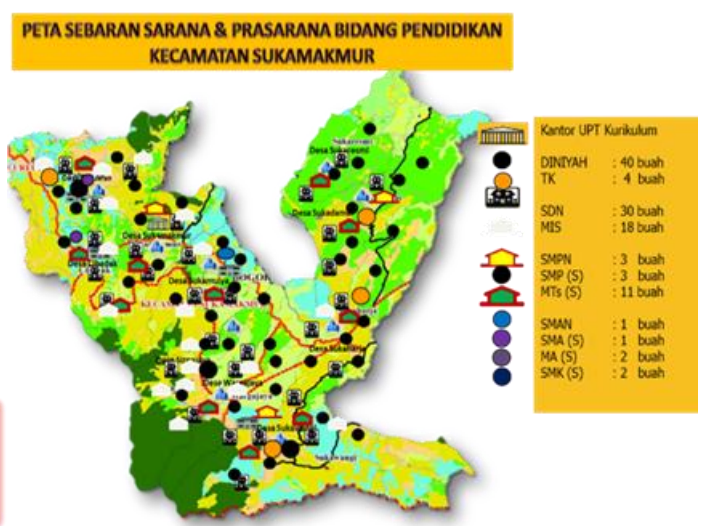

Sukamulya. Yaitu PKBM Roudatul, Putra Mandiri, Al fikri dan PKBM An Nur. PKBM yang ada memberikan harapan bagi masyarakat untuk tetap dapat menempuh pendidikan minimal SMA agar dapat bekerja. Di beberapa desa masih ditemukannya buta aksara 
pada usia sekolah hal ini sebabkan karena mereka putus sekolah di kelas rendah karena SD negeri yang jauh, penyebab lainnya kesadaran orang tua yang belum menyadari pentingnya pendidikan, manfaat pendidikan dasar bagi anak anaknya. Selain hal tersebut anak anak tersebut ada yang hanya sekolah sampai kelas tiga, sehingga mereka mengenal huruf tetapi tidak bisa membaca perkata ataupun perkalimat.

Kondisi ini menyebabkan tutor harus meningkatkan kompetensi sebagai pendidik agar peserta didik termotivasi dalam proses pembelajaran. Bukan hanya tutor, pengelola harus memiliki kemampuan dalam melakukan perencanaan, proses dan evaluasi dalam mendukung proses pembelajaran. Pelaksanaan proses pembelajaran tutor menghadapi berbagai kendala dalam metode pembelajaran, pengembangan media dan pengembangan instrumen kebutuhan belajar bagi peserta didik orang dewasa (Rifai ; 2009). Berdasarkan kondisi ini perlu adanya solusi untuk mengatasi berbagai kendala yang dihadapi oleh tutor untuk mendukung proses pembelajaran agar dapat berjalan maksimal dan sesuai dengan kebutuhan belajar peserta didik. Salah satunya mengembangkan media pembelajaran berbasis Android. Selama ini tutor masih menggunakan metode ceramah dan terbatas menggunakan media. Penggunaan media berbasis Android masih memiliki kelebihan dan manfaat bagi tutor maupun bagi peserta didik untuk dapat meningkatkan motivasi belajar. (Cecep, dkk ; 2011) .
Pembelajaran menggunakan media yang berbasis androdid sebagai upaya menguatkan pemahaman peserta didik terhadap materi yang disajikan, dan peserta didikpun dapat mengaksesnya dimanapun ia berada untuk mengatasi persoalan peserta didik yang tempat tinggalnya jauh dari PKBM. Pengajaran menggunakan media berbasis android ini juga mampu menekankan pada praktik literasi digital secara langsung yang tetap mengacu pada konsep teori media pembelajaran untuk pendidikan kesetaraan. Pembelajaran menggunakan media berbasis Android mampu digunakan dimana saja peserta didik itu berada, maka dari itu kemandirian peserta didik akan meningkat karena tanpa kehadiran pendidikpun, peserta didik mampu mengoperasikannya. Penyajian yang disediakanpun mampu menarik minat peserta didik, karena berisi sebuah materi yang disajikan melalui video, sehingga peserta didik tidak merasa bosan dan jenuh, karena media tersebut dapat merangsang kemampuan melihat dan mendengar peserta didik (Mudlofir ; 2016).

\section{Permasalahan Mitra}

Berdasarkan analisis siatuasi dan kondisi maka diperlukan adanya beberapa hal untuk mendukung peningkatan Kompetensi Tutor dan Pengelola agar peserta didik mandiri dalam proses pembelajaran di PKBM adalah sebagai berikut:

a. Media Pembelajaran Android
Media pembelajaran bisa
dikatakan sebagai alat yang bisa 
merangsang peserta didik agar dapat terjadi sebuah proses belajar. Media tidak hanya berupa alat atau bahan saja. Tapi juga hal-hal lain yang memungkinkan peserta didik memperoleh pengetahuan. Berdasarkan hal itu, media pembelajaran akan dapat menyalurkan pesan yang hendal disampaikan, merangsang pikiran serta kemauan peserta didik sehingga dapat mendorong terciptanya proses belajar pada diri peserta didik itu sendiri. Berdasarkan beberapa pendapat diatas dapat ditarik kesimpulan bahwa, media pembelajaran merupakan segala bentuk yang dipakai atau digunakan sesorang ataupun pendidik dalam hal ini biasanya pengajar untuk menyalurkan informasi atau bahan ajar yang mengandung maksud dan tujuan pembelajaran sehingga dapat merangsang pikiran peserta didik agar dapat lebih tertarik selama kegiatan pembelajaran berlangsung.

\section{b. Perencanaan Pembelajaran}

Pembelajaran bisa maksimal jika pendidik mampu mempersiapkan segala hal dengan sedemikian rupa, termasuk mempersiapkan media pembelajaran. Berikut merupakan langkah-langkah membuat media pembelajaran berbasis Android (Syafaat ; 2012):

1) Mempersiapkan video yang menarik

Untuk menyampaikan materi pembelajaran, pendidik harus membuat atau mencari video yang berhubungan dengan materi tersebut. Adapun video yang dipilih merupakan video yang sesuai, singkat, jelas dan manarik sehingga maksud dari materi dapat tersampaikan serta peserta didikpun tertarik untuk menyaksikan video secara utuh dan mempelajari isi video tersebut.

2) Mengupload video ke youtube Setelah mendapatkan video yang sesuai, selanjutnya ialah dengan menguplaod video tersebut ke youtube. Karena pranala (link) dari video pada youtube tersebut dapat digunakan sebagai syarat untuk membuat aplikasi pada android.

3) Membuat kalimat stimulus Hal yang tidak kalah penting ialah dengan tetap memperhatikan keadaan peserta didik, agar peserta didik merasa dianggap ada, baiknya gunakan kalimat yang memiliki kesan peduli, serta tuliskan kalimat stimulus agar peserta didik merespon untuk melakukan tindakan yang baik, dalam hal ini mempelajari materi dengan sungguh-sungguh.

4) Membuat section identitas diri (Biodata)

Hal ini bertujuan untuk memudahkan pendidik mengetahui siapa saja yang mengoperasikan media tersebut.

5) Memasukan video ke google form Selanjutnya ialah dengan memasukan video ke google form, hal ini bertujuan agar pada saat peserta didik menggunakan aplikasi maka video tersebut akan tampil setelah peserta didik mengkliknya.

6) Menulisakan soal evaluasi 
Hal ini bertujuan untuk mengukur kemampuan peserta didik, apakah sudah menguasai materi atau belum, sehingga dapat ditindaklanjuti sesuai dengan hasil penilaian.

7) Membuat respon yang mengapresiasi peserta didik

Setiap peserta didik memilki kemampuan yang berbeda dalam mempelajari suatu materi, tugas pendidik ialah dengan merespon dalam bentuk mengapresiasi. Jika peserta didik sudah menjawab dengan benar maka diberi ucapan selamat. Namun jika peserta didik belum menjawab dengan benar maka beri ucapan yang tetap membangun kepercayaan diri peserta didik serta menjelaskan jawaban yang benarnya sehingga peserta didik bisa langsung mempelajarinya secara langsung.

8) Membuat aplikasi

Setelah google form lengkap, langkah selanjutnya ialah dengan membuat media pembelajaran menjadi sebuah aplikasi yang dapat di instal di Android. Dalam hal ini menggunakan aplikasi appgeyser.

c. Pelaksanaan Pembelajaran

1) Peralatan Sederhana Yang Dipergunakan Dalam Kegiatan Belajar Dan Mengajar Di Berbasis Android

Kegiatan belajar mengajar menggunakan media berbasis androis juga membutuhkan peralatan. Namun, peralatan yang dibutuhkan sangat sederhana. Berikut adalah beberapa peralatan yang dapat dibutuhkan dalam

kegiatan pembelajaran menggunakan media berbasis android.

a) Android

Peserta didik harus memilki android untuk memasang aplikasi.

b) Laptop

Pendidik bisa memantau melalu database pada laptop, pendidik bisa mengetahui siapa saja yang sudah menoperasikan aplikasi serta pendidikpun juga mengetahui skor peserta didik.

c) Internet

Setiap android harus terhubung dengan internet, agar aplikasi tersebut bisa dioperasikan.

2) Materi-Materi Yang Menggunakan Media Berbasis Android

Pada prinsipnya, hampir semua mata pelajaran di PKBM dapat disampaikan dengan menggunakan media berbasis Android, tergantung pada ketersediaan video yang bersangkutan. Namun seorang Tutor harus memilih materi apa yang sekiranya perlu menggunakan media berbasis android, karena penggunaan media ini untuk menambah pemahaman peserta didik.

\section{Solusi Permasalahan}

Berdasarkan potensi dan permasalahan yang ada tutor dan pengelola maka perlu membuat program yang dapat meningkatkan kemampuan kompetensi tutor dalam mengembangkan media pembelajaran dan peran pengelola dalam mendukung 
proses pembelajaran di PKBM. Sesuai dengan kebutuhan maka pengabdian masyarakat terintegrasi dengan $\mathrm{KKN}$ dirancang untuk tiga tahun ke depan sebagai berikut ini:

1. Program dan Luaran

Tabel 1. Program Dan Luaran

\begin{tabular}{|c|c|c|c|c|}
\hline SOLUSI & TARGET & $\begin{array}{c}\text { TAHUN } \\
\text { PERTAMA }\end{array}$ & $\begin{array}{l}\text { TAHUN } \\
\text { KEDUA }\end{array}$ & $\begin{array}{l}\text { TAHUN } \\
\text { KETIGA }\end{array}$ \\
\hline \multirow[t]{2}{*}{$\begin{array}{l}\text { Pelatihan } \\
\text { Media } \\
\text { Pembelajaran } \\
\text { Berbasis } \\
\text { Android }\end{array}$} & $\begin{array}{l}\text { Mampu } \\
\text { melaksanakan/ } \\
\text { mengoperasikan } \\
\text { media } \\
\text { pembelajaran } \\
\text { berbasis android }\end{array}$ & $\begin{array}{l}\text { Upaya untuk } \\
\text { meningkatkan } \\
\text { pemahaman } \\
\text { tentang media } \\
\text { pembelajaran } \\
\text { berbasis android }\end{array}$ & $\begin{array}{l}\text { Upaya untuk } \\
\text { meningkatkan } \\
\text { kemampuan } \\
\text { dalam } \\
\text { perencanaan } \\
\text { pembuatan } \\
\text { media berbasis } \\
\text { Android }\end{array}$ & $\begin{array}{l}\text { Upaya untuk } \\
\text { menggunakan, } \\
\text { melaksanakan, } \\
\text { mengoperasikan } \\
\text { media } \\
\text { pembelajaran } \\
\text { berbasis Android }\end{array}$ \\
\hline & Aktivitas & $\begin{array}{l}\text { Pelatihan tentang } \\
\text { Media } \\
\text { Pembelajaran } \\
\text { Berbasis Android } \\
\text { Konsep dan } \\
\text { Pemahaman }\end{array}$ & $\begin{array}{l}\text { Pelatihan } \\
\text { Membuat } \\
\text { Perencanaan } \\
\text { Media } \\
\text { pembelajaran } \\
\text { Android }\end{array}$ & $\begin{array}{l}\text { Pelatihan Praktek } \\
\text { Pembuatan dan } \\
\text { Mengoperasikan } \\
\text { Media } \\
\text { Pembelajaran } \\
\text { Berbasis Android }\end{array}$ \\
\hline
\end{tabular}

2. Rencana Target Capaian

Hal di atas sebagai program yang akan dilaksanakan dapat meningkatkan kemampuan Tutor dan Pengelola:

a. Meningkatkan kemampuan tutor dan pengelola dalam menggunakan media pembelajaran berbasis Android.

b. Meningkatan kemampuan tutor dan pengelola dalam merencanakan pembelajaran dengan menggunakan media pembelajaran berbasis Android

c. Memandu tutor dan pengelola dalam melaksanakan pembelajaran menggunakan media pembelajaran berbasis Android

d. Memandu tutor dan pengelola dalam menilai pembelajaran menggunakan media pembelajaran berbasis Android

\section{METODE PELAKSANAAN Persiapan dan Pembekalan}

Hasil di lapangan menunjukkan tutor dan pengelola di dorong untuk dapat mengingkatkan kemampuan untuk dapat meningkatkan kemandirian peserta didik dalam belajar dengan menggunakan media pembelajaran berbasis android. Maka perlu persiapan dan pembekalan bagi team untuk merencanakan dan melaksanakan kegiatan tersebut. Adapun mekanismenya sebagai berikut:

a. Melakukan koordinasi dengan stakeholder ditempat pelaksanaan berlangsung. Koordinasi dengan pihak terkait terdiri atas: Kecamatan, 
Dinas Pendidikan dan Pengelola PKBM.

b. Koordinasi dengan Pengelola PKBM di setiap PKBM yang ada di Kecamatan Sukamakmur.

c. Mensosialisasikan kepada pengelola dan tutor untuk mengikuti pelatihan.

d. Team memperpersiapkan rancangan program dan evaluasi setelah program selesai dilaksanaan.

e. Menempatkan Mahsiswa di Lokasi pelaksanaan pelatihan.

f. Mempersiapkan mahasiswa untuk membantu pelaksanaan program.

\section{Pelaksanaan Program Pendampingan}

Pelaksanaan dapat berjalan dengan

baik maka diperlukan langkah kegiatan:

a. Melakukan pendataan peserta yang akan mengikuti pelatihan

b. Membuat jadwal kegiatan pelaksanaan pelatihan

c. Membuat materi program sesuai dengan kegiatan.

d. Melakukan evalusi sebelum program, proses dan sesudah program.

e. Melakukan pendampingan

\section{Evaluasi Kegiatan Pelatihan}

a. Pada akhir pelatihan akan dilakukan pendataan ulang tutor dan pengelola yang telah mengikuti pelatihan.

b. Evaluasi kebermanfaatan pelatihan sesuai dengan kebutuhan masyarakat.

c. Memberikan penghargaan kepada tutor dan pengelola yang memilik aktivitas pembelajaran yang cukup terpenuhi dari segi kehadiran, motivasi dan disiplin belajar.
Sesuai dengan rencana pelaksanaan kegiatan program pengabdian masyarakat ini dapat dilakukan selama 4 (empat) bulan yaitu mulai bulan Juli sampai dengan Oktober 2019. Dengan rincian kegiatan sebagai berikut:

a. Rapat Koordinasi, Tanggal 24 Juli 2019 di Ruang Kaca FIP

b. Survei Lokasi Tanggal 31 Juli 2019 Kec. Sukamakmur

c. Pendataan Peserta Peatihan, tanggal 1 Agustus 2019 di Desa Pabuarsn

d. Pembukan Kegiatan PkM, Tanggal 20 Agustus 2019 di Aula Kec. Sukamakmur

e. Pelaksanaan Pelatihan Tanggal 2021 Agustus 2019 di Aula Kec. Sukamakmur

f. Pelatihan lanjutan, Tanggal 18-19 Agustus 2019 di Desa Pabuaran

g. Pendampingan Media Android Tanggal 20-21 September 2019 di lokasi PKBM

h. Penutupan dan Evaluasi kegiatan, Tanggal 26 September 2019 di Desa Pabuaran.

\section{HASIL DAN PEMBAHASAN Deskripsi Kegiatan}

Pelaksanaan kegiatan pengabdian kepada masyarakat yang terintegrasi dengan Kuliah Kerja Nyata mahasiswa program studi Pendidikan Masyarakat Fakultas Ilmu Pendidikan UNJ tentang pelatihan penyusunan media android bagi Tutor dan Pengelola PKBM di Kecamatan Sukamakmur Kabupaten Bogor. Kegiatan pelatihan ini dilaksanakan dua tahapan. Pertama pemberian materi secara teoritis pada tanggal 20 Agustus 2019 bertempat

\section{Jadwal Kegiatan}


di Aula Kecamatan Sukamakmur dari pukul 09.00 sampai dengan 15.30 WIB.

Kegiatan pelatihan tahap pertama ini diawali dengan pembukaan acara pengabdian kepada masyarakat yang di hadiri oleh pejabat Kecamatan Sukamaakmur, Penilik PAUD Dikmas dan Para Dosen serta mahasiswa dari Prodi PenMas yang dilibatkan sebagai Mahasiswa KKN. Adapun peserta yang hadir dalam pelatihan tahap pertama penyusunan media android sebanyak 25 orang terdiri dari tutor dan pengelola
PKBM Sukamakmur, PKBM Putra Mandiri dan PKBM Sirnajaya.

Kegiatan pelatihan tahap pertama ini diawali dengan menyanyikan lagu Indonesia Raya yang diikuti oleh pihak Kecamatan Sukamakmur yaitu Pak Sekretaris Kecamatan dan Para dosen perwakilan program Pendidikan Masyarakat Fakultas Ilmu Pendidikan UNJ serta Penilik Pendidikan Masyarakat dan para pengelola serta Tutor Pendidikan Kesetaraan Paket C.

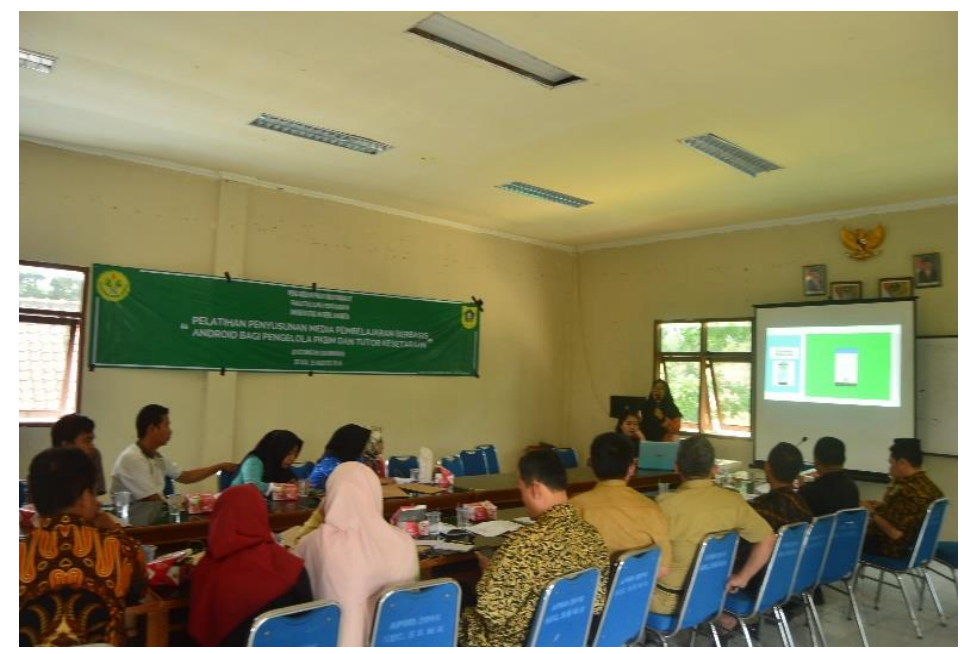

Gambar 2. Perwakilan Kaprodi dan Dosen PLS Yang Hadir Dalam Kegiatan Pelatihan

Pada kegiatan selanjutnya dengan pemaparan materi yang menghadirkan Narasumber yang kompeten dalam penyusunan media android bagi tutor dan pengelola PKBM yaitu Ibu Nia Anggraeni S.Pd dengan memberikan uraian tentang Media berbasis Android secara konsep dan praktis untuk menyusun media Pembelajaran Mandiri Bagi Tutor Kesetaraan di PKBM. Peserta kegiatan tampak antusias dan serius di dalam mendengarkan paparan materi. Materi penyusunan media berbasis Android dalam pembelajaran mandiri merupakan suatu hal yang sangat positif bagi tutor kesetaraan didalam menambah kompetensi mereka pada pembelajaran. Berlangsungnya pelatihan bisa link: https://youtu.be/ak4TD1Mot00 


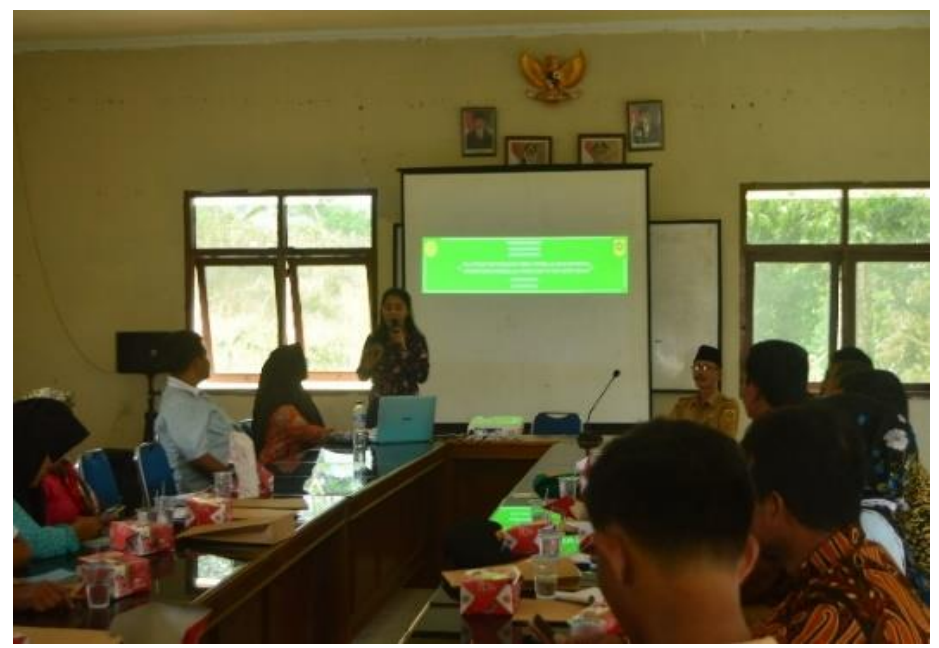

Gambar 3. Pemaparan Materi Dari Tim Pengabdian Kepada Masyarakat

Setelah materi disampaikan, Pemateri kemudian memberikan kesempatan kepada para peserta kegiatan untuk memberikan pertanyaan mengenai materi yang belum dimengerti. Selanjutnya, pemateri membagi peserta menjadi beberapa kelompok untuk melakukan diskusi dan kegiatan praktek langsung didalam menyusun media pembelajaran mandiri. Anggora kelompok kemudian menunjukkan pemahamanya didalam menyusun media kepada pemateri untuk diberikan dan disikusikan secara bersama-sama.

Setalah kegiatan pelatihan tahap pertama selesai, tim pelaksana kegiatan pengabdian kepada masyarakat kemudian menutup acara. Sebelum menutup kegiatan pelatihan, Ketua tim pengabdian kepada masyarakat yang terintegrasi KKN memberikan apresiasi yang bagus atas terselengggara kegiatan pelatihan pada satu hari pertama ini. Mengingat bahwa masih banyaknya para tutor dan pengelola PKBM yang belum memiliki pemahaman secara praktisnya dalam menyusun media pembelajaran berbasis Android. Sehingga kegiatan pelatihan tersebut akan dilanjutkan dengan kegiatan pendampingan yang akan dilakukan oleh mahasiswa yang KKN sebanyak lima orang

Tahap kedua dalam kegiatan pengabdian kepada masyrakat yang terintegrasi KKN dilaksanakan pada tanggal 18-19 September 2019 di Lembaga PKBM masing-masing untuk menindaklanjuti hasil pelatihan yang telah dilaksanakan pada tahap pertama tanggal 20 Agustus 2019 di Aula Kantor Kecamatan Sukamakmur. Adapun kegiatan pendampingan penyusunan media pembelajaran berbasis android mulai pada PKBM Putra Mandiri Desa Pabuaran yang diikuti oleh 11 orang peserta dengan tim pendamping mahasiswa KKN sebanyak 5 orang yaitu: (1) Anindyajati Priyandita/ NIM. 1515162343, (2) Anastasya Siam/ NIM. 1515160053, (3) Sulistya Anjar/ NIM. 1515161845, (4) Mayang Salsabila Lubis/ NIM. 1515160702 dan (5) Ayub Pratama/ NIM. 1515161699.

Bagaimana proses berlangsungnya kegiatan pendampingan dapat dilihat pada 
dokumen lengkapnya link di youtube:

https://www.youtu.be/F_Ati8rEAZs

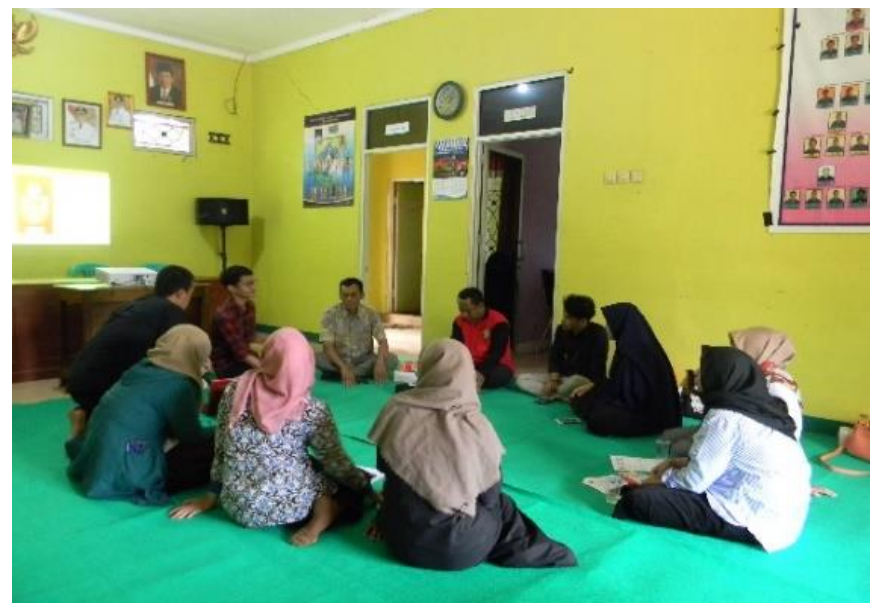

Gambar 4. Proses Pendampingan Penyusunan Media Android

\section{PENUTUP}

Pelaksanaan kegiatan pengabdian kepada masyarakat yang terintegrasi dengan Kuliah Kerja Nyata mahasiswa program studi Pendidikan Masyarakat Fakultas Ilmu Pendidikan UNJ tentang pelatihan penyusunan media android bagi Tutor dan Pengelola PKBM di Kecamatan Sukamakmur Kabupaten Bogor dapat disimpulkan.

1. Pemberian pelatihan pada tanggal 20 Agustus 2019 dengan materi Penyusunan Media Pembelajaran Berbasis Android secara teori. Dengan jumlah peserta sebanyak 25 orang dengan tempat di Aula Kecamatan Sukamakmur dari pukul 09.00 sampai dengan $15.30 \mathrm{WIB}$.

2. Pendampingan oleh mahasiswa KKN tentang pembuatan media pembelajaran berbasis android pada tanggal 18-19 September 2019 di PKBM masing-masing untuk menindaklanjuti hasil pelatihan yang telah dilaksanakan pada tahap pertama tanggal 20 Agustus 2019 di Aula Kantor Kecamatan Sukamakmur.

\section{DAFTAR PUSTAKA}

Dimyati dan Mudjiono. 2009. Belajar dan Pembelajaran . Jakarta. PT. Rineka Cipta.

Gintings, Abdurarakhman. 2008. Belajar Dan Pemebelajaran. Bandung: Humaniora.

KBBI. 2016. Tutorial. Versi1.9. (Online) (http://kbbi.web.id/tutorial) 14 Februari 2016

Petunjuk Teknis Penyelenggaraan Program Pendidikan Kesetaraan. 2015. Kementerian Pendidikan dan Kebudayaan Ditjen PAUD dan Dikmas, Direktorat Pembinaan Pendidikan Masyarakat.

Sagala, Syaiful, 2012. Konsep dan Makna Pembelajaran, Bandung: Alfabeta

Syafaat, Nazzrudin, 2012. Pemprograman Aplikasi Mobile Smartphone dan

Sarwahita : Jurnal Pengabdian Kepada Masyarakat Vol. 18 No. 2 Tahun 2021 | 155 
Tablet PC Bebasisi android. Ngalimun, 2016. Strategi dan Model Informatika, Bandung. Pembelajaran, Yogyakarta: Aswaja Pressindo

Rifa'I RC, Ahmad, 2009. Desain Kelas, Jakarta: Prestasi Pustaka Pembelajaran orang dewasa, Semarang: Unnes Press

Kustandi, Cecep, dan Bambang Sutjipto, 2011. Media Pembelajaran, Jakarta: Ghalia Indonesia

Hamiyah, Nur, dan Mohammad Jauhar, 2014. Strategi Belajar-Mengajar di Jakarta

Arsyad, Azhar, 2017. Media Pembelajaran, Jakarta: Rajawali Pers

Mudlofir, Ali, dan Evi Patimatur Rusydiyah, 2017. Desain Pengembangan Inovatif, Jakarta: Rajawali Pers 